eCommons@AKU

February 2007

\title{
Pakistani physicians and the repatriation equation
}

Saad Shafqat

Aga Khan University, saad.shafqat@aku.edu

Anita K. M. Zaidi

Aga Khan University, anita.zaidi@aku.edu

Follow this and additional works at: https://ecommons.aku.edu/pakistan_fhs_mc_med_neurol Part of the Neurology Commons

\section{Recommended Citation}

Shafqat, S., Zaidi, A. (2007). Pakistani physicians and the repatriation equation. New England Journal of Medicine, 356, 442-443. Available at: https://ecommons.aku.edu/pakistan_fhs_mc_med_neurol/88 
training followed by a year of internship. Although all health care workers are subject to the pull of emigration, the global market for midlevel practitioners is not standardized, and the government hopes that most medical assistants will remain in Ghana.

There are some physician reinforcements available, particularly from Cuba - currently, 200 Cuban doctors make up $7 \%$ of Ghana's physician workforce. But when I asked a class of Ghanaian medical students how many of them would like to go abroad for further study after graduation, virtually every hand went up. When I asked, "How many of you think you would come home again?" about half the hands went down. Many of them see their futures in New York or London, where they believe professional and income opportunities will outweigh any hardships associated with leaving their country. Given the massive economic imbalance between the West and Africa, even the most creative domestic employment strategies may not do much to curtail this ambition.

Nonetheless, much can be done in the developed world to help build the health workforces of developing countries, including continued investments in training and retention programs and an increased commitment by U.S. health care professionals to work in developing countries. However, the single most important contribution that the United States could make would be to train more doctors at home. About 25\% of the physicians practicing in the United States went to medical school abroad - as did roughly the same proportions in the United Kingdom, Canada, and Aus-

\section{Pakistani Physicians and the Repatriation Equation}

Saad Shafqat, M.B., B.S., Ph.D., and Anita K.M. Zaidi, M.B., B.S.

In Pakistan, students who are

accepted into medical school are congratulated - only halfjokingly — on three counts: that they will become doctors, that they will become certified by the American Board of Medical Specialties, and that they will soon be living in the United States.

Pakistan has contributed approximately 10,000 international medical graduates (IMGs) to the United States, ${ }^{1}$ even though it faces a shortage of physicians. ${ }^{2}$ Take the case of Aga Khan University Medical College in Karachi. By 2004, it had produced 1100 graduates, 900 of whom had gone on to graduate medical training in the United States despite the fact that doing so costs up to $\$ 20,000$ (a fortune for most Pakistanis) and means leaving the comforts of one's home and culture.

The United States represents an overpowering lure: a rigorous system of graduate medical education, a merit-based structure of professional rewards, and a culture of academic nurturing. And, of course, material rewards. In Pakistan, an intern earns approximately $\$ 150$ per month (the same salary as an unskilled, illiterate worker), whereas a U.S. intern can afford to live independently - and expect a better quality of life after residency.

Information from Pakistani medical institutions indicates that only about 300 of the 10,000 U.S.trained Pakistani physicians have resettled back home. Why did this minority choose to return? Aga Khan's experience is instructive: the majority of the medical school's 40 or so alumni who have repatriated from the United States have joined its faculty.

Motives for returning include aging parents and family ties, a desire to raise children in a familiar culture, and an emotional need to be home. But for many Aga Khan returnees, the attributes of the university and its hospital were key: teaching, research, and clinical care are patterned after the U.S. model, and salaries permit a comfortable lifestyle. Ultimately, attractive career prospects have to be the draw.

The challenge is local capacity to absorb highly trained physicians. U.S.-trained physicians represent a small fraction of Pakistan's 116,000 doctors, ${ }^{2}$ but they return with ambitions to set new standards for clinical practice, education, and research and to influence academic medicine, health policy, and public health. To do so, they must negotiate local circumstances for which they are unprepared: exhausting clinical demands, an impoverished population, an environment in which malnutrition is a significant cause of death, collapsed health care delivery systems, and patients who respond to an unjust society with mistrust. Inevitably, they also face questions from local professionals about the appropriateness of U.S. training for practice in Pakistan.

Discussions with expatriate physicians indicate that many more wish to return but cannot find suitable jobs. Like many poor countries, Pakistan has 
both severe shortages of health care professionals and a high level of unemployment among physicians - a paradox caused by inadequate and inappropriate investment in local health care systems. Elite medical academies in developing countries are frequently derided as manufacturers of a product that, out of place in its environment, enters a workforce supply chain leading to the West. ${ }^{1,3}$ The answer, however, is not to lament the irrelevance of these institutions but to advocate for more - for they can attract back highly trained professionals who have the potential to assume leadership roles. Repatriated Aga Khan graduates have won grants from major international agencies, established nonprofit research organizations, joined hospitals serving refugee populations, and led disease-control programs. Such academic institutions can play pioneering roles if they reorient their priorities to match their countries' needs - producing professionals with a strong public health ethic, establishing rigorous graduate programs in which trainees are paid good wages, and developing relationships with alumni that can help sustain rewarding careers in challenging environments.

Exhorting physicians to serve in environments to which their skills are ill-suited will not lure IMGs home. Barriers to immigration in individual countries are almost meaningless in a globalized world. For example, as immigration laws in Western countries are tightened, Pakistani physicians are seeking jobs in the Middle East. We believe that developed countries that import physicians to meet their own de- mands have a moral obligation to invest in improving health care systems in countries that train substantial segments of their workforce. Such investments provide employment opportunities for the diaspora of health care professionals, benefiting health in developing countries.

As a first step, the U.S. medical community can support IMGs who want to repatriate. U.S. academic medical centers could work with institutions in developing countries to develop training programs oriented toward global health, ${ }^{4}$ availing themselves of growing funding opportunities for such endeavors. ${ }^{5}$

One approach is to offer motivated IMGs mentoring to equip them with skills needed in their home countries. The scheme could be formalized through international cross-appointments for mentor and mentee at each other's institutions and a bilaterally recognized role for the mentor. Such initiatives are desperately needed; properly done, repatriation of IMGs can help diminish vast disparities in health care.

Dr. Shafqat is an associate professor of neurology, and Dr. Zaidi an associate professor of pediatrics and microbiology, at Aga Khan University Medical College, Karachi, Pakistan.

1. Mullan F. The metrics of the physician brain drain. N EnglJ Med 2005;353:1810-8.

2. Working together for health: the World Health Report 2006. Geneva: World Health Organization, 2006. (Accessed January 11, 2007, at http://www.who.int/whr/2006/ whr06_en.pdf.)

3. Bundred PE, Levitt C. Medical migration: who are the real losers? Lancet 2000;356:245-6.

4. Institute of Medicine. Who will keep the public healthy? Educating health professionals for the 2lst century. Washington, DC: National Academies Press, 2003.

5. Gupta R, Hotez P. Rethinking global health training in North America. Medscape General Medicine. August 24, 2006.

Copyright () 2007 Massachusetts Medical Society. tralia. ${ }^{5}$ For years, we have been educating about three quarters of the doctors we need and relying on the rest of the world to supply the balance. For 25 years, the number of students admitted to U.S. allopathic medical schools has remained constant, while the number of physicians we import has climbed steadily. Without ever enunciating a strategy of dependence on the world, we have created a huge U.S. market for physicians educated elsewhere, inadvertently destabilizing the medical systems of countries that are battling poverty and epidemic disease.

A commitment in the United States to ramp up medical school opportunities to a level closer to national needs would do much to slow medical migration and bring stability to medical programs in poorer countries. Perhaps soccer players will always migrate to the elite leagues of the world, but if doctors and nurses stayed closer to home, lives would be saved.

An interview with Dr. Mullan can be heard at www.nejm.org.

Dr. Mullan is a professor of pediatrics and health policy at George Washington University, Washington, DC.

1. Joint United Nations Programme on HIV/ AIDS (UNAIDS). 2006 Report on the global AIDS epidemic. (Accessed January 11, 2007, at http://data.unaids.org/pub/GlobalReport/ 2006/2006_GR_CH02_en.pdf.)

2. WHO Department of Reproductive Health and Research. Monitoring and evaluation (MAE). Geneva: World Health Organization, July 31, 2006. (Accessed January 11 , 2007, at http://www.who.int/en/.)

3. Johnson K, Rutstein S, Govindasamy P. The stall in mortality decline in Ghana: further analysis of demographic and health surveys data. Calverton, MD: ORC Macro, 2005. (Accessed January 11, 2007, at http://www. measuredhs.com/pubs/pdf/FA47/FA47.pdf.)

4. The Joint Learning Initiative. Human resources for health: overcoming the crisis. Cambridge, MA: Harvard University Press, 2004.

5. Mullan F. The metrics of the brain drain. N Engl J Med 2005;353:1810-8.

Copyright $(2007$ Massachusetts Medical Society. 